\title{
Gender and Welfare Regimes Revised Connecting Danish and Chinese Perspectives
}

\section{By Peter Abrahamson}

\begin{abstract}
Gender and Welfare Regimes Revised. Connecting Danish and Chinese Perspectives

China and Denmark could hardly be more different cases for comparison: a huge developing one-party state set against a small post-industrial plural state. Despite these significant and categorical differences, however, both states are faced with similar challenges when it comes to changing demographic patterns, with more elderly persons in need of both care and support, coupled with smaller working-age populations to deliver that care and support. Mapping and comparing the combinations of welfare regarding care for the elderly in China and Denmark reveals serious inequalities of class, gender and generation. Both states are in principle fully committed to the wellbeing of all citizens through universal welfare state protection, but in reality both rely very much on market and civil society solutions, which leaves the population strongly differentiated and polarized, not only when it comes to gender and generation, but also with respect to class. The conclusion is that Denmark and China are converging towards a model of welfare combinations set within an overall framework of universalism. The most important lines of conflict revolve around generation, though class and gender also remain influential.
\end{abstract}

\section{KEYWORDS}

China, Denmark, welfare regime, elderly care, gender, generation

Peter Abrahamson is Associate Professor, Department of Sociology, University of Copenhagen. His research focuses on comparative welfare systems. Related books: Understanding Social Policy in Europe (Co-edited with Christian Aspalter), Taipei: Casa Verde Publishing 2008; and Welfare and Families in Europe (co-authors: Thomas P. Boje and Bent Greve), Aldershot: Ashgate, 2005. 


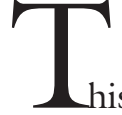

his article situates Denmark and China respectively within the Scandinavian and East Asian welfare regimes, thus underlining the substantial differences between the two. However, the discussion of how support and care for the frail and elderly is organized, financed and provided reveals remarkable similarities between the Chinese and Danish cases. Focusing on gender and generation, class also serves as a dividing line in both societies. Developments in Denmark are interesting from the Chinese perspective, since they point to a solution for the care deficit problem in China, namely the introduction of publicly financed and publicly regulated care. Simultaneously, China is also interesting from a Danish perspective, since it demonstrates the issues involved in intergenerational exchanges and solidarities, which are also on the increase in Denmark.

The article provides an overview of the gender regime that prevails in post-revolution China, that is, since the creation of the People's Republic of China in 1949. It points out the persistent problems of women's inferior labor market positions vis-à-vis men, which are exacerbated when it comes to child birth, maternity leave and care. By focusing on the most recent developments in Shanghai, these problems are illustrated in their most developed forms in China. This is followed by a parallel discussion of the organization of combinations of welfare in Copenhagen with respect to care for the elderly, highlighting the importance of institutions in civil society and NGOs, despite the strong traditional ideological orientation towards the public sector.

The article concludes that Denmark and China are converging towards a model of welfare combinations set within an overall framework of universalism. The most important lines of conflict are identified as revolving around generation, though class and gender also remain influential.

\section{Welfare AND GENDER REgimes, EAST AND WEST}

Denmark belongs to the so-called Scandinavian welfare regime, which is characterized by being universal, comprehensive, financed through taxation, and as emphasizing public care services for children, the disabled and the frail and elderly. These conditions have enabled women to work full time (or long-term part-time) and to have children at the same time. Labor markets are highly organized, and wage variation is low. However, male employment is biased toward the private sector, while female employment is biased toward the public sector, resulting in women having lower incomes but more secure employment than men. Welfare spending is high, but the comprehensive care services make it possible to reconcile work and family life, which results in an absolute fertility rate close to 2.0. This scenario has been defined as women-friendly, or at least as having women-friendly potential (Hernes 1987). Though backed by policies emphasizing equal treatment, in everyday life women still have more responsibilities than men for providing care to family members and keeping house (Borchorst 2012).

Following Ian Gough et al. (2004) and Wood and Gough (2006), I previously suggested that welfare regimes in southern Europe, Latin America and East Asia have a lot in common: all three regions are late industrializers and late democratizers, and they all have a long tradition, legally and morally, of filial piety, meaning that the eldest son of the family is responsible for the well-being of elderly family members. This responsibility for care often falls on the wife and sisters of the eldest son. Women work a lot, but mostly within the informal sector, which does not necessarily provide access to welfare benefits. The states in these regions are all characterized by being small spenders when it comes to 
social policy. Furthermore, with the exception of Latin America, women in these regions also show low levels of fertility. As a result, the label 'informal care regime' has been attached to welfare states in these regions (Abrahamson 2011).

Concerning China, it is well known that its development has been extremely rapid, especially with respect to economic growth, but more recently that has been the case regarding social rights as well. Hence, from a Scandinavian perspective it is of great interest to observe China committing itself to developing a universal welfare system in the most recent five-year plan (China Development Research Foundation 2012). At least on paper, the plan entails major changes, especially compared to the period following the opening up of the economy in the late 1970s. Gradually, systems of social protection have been established through health, old-age insurance and social assistance, while social service provision has remained rudimentary (Chan, Ngok, Philips 2008; Kettunen, Kuhnle, Ren 2014). This recent commitment to universal social citizenship is strongly motivated by a fear of declining social cohesion because of the significant increases in social inequality that have resulted from the massive, but unevenly distributed economic growth.

\section{Generations of CARE:}

\section{Comparing ChIna AND DENMARK}

Relationships between welfare and gender regimes can be demonstrated with respect to how care is produced and distributed in society. Reflecting on the situation during the 1980s and 1990s, the Danish and Chinese cases could hardly be more different. Denmark is seen as the realization of the universal or Beveridge-style welfare model developed during the 1980s and onwards, characterized by a comprehensive system of municipal care arrangements for the elderly, as well as for other groups such as young children. There exists a guarantee of child care to all parents, ensuring that they could have their child or children taken care of in public nurseries, kindergartens and after-school clubs. Universal guarantees of care for the disabled have also been continued and expanded. Hence, parents are relieved of the care burden, making it possible for Danish women both to undertake labor market careers and to retain the main responsibility for raising children. Furthermore, financial transfers to all families with children have been increased over the same period, making it easier, if still difficult, to raise children (Abrahamson 2010).

In general, social policy reforms have come about on the basis of a wide range of compromises and a high degree of consensus in the Nordic countries, particularly concerning family policy (Abrahamson 2014). As mentioned above, from one perspective this has led to the creation of a women-friendly welfare state, which is reflected in the relatively high levels of fertility and can be seen as a victory for the fight for equal treatment of men and women. However, women in Scandinavia still earn less than men and have less influential positions within labor hierarchies. Hence, it can also be claimed that welfare state arrangements have made it possible for women to perform a double duty as both mothers and workers.

The position regarding family policy and women in China is different. For instance, care for needy family members was a joint responsibility organized by the eldest son in accordance with more than 2000 years of the Confucian principle of filial piety. Historically, this has been the dominant principle all over the world. From a reproductive point of view, this functioned well as long as families had many children, who stayed at or close to home. However, this situation is being seriously challenged by two major developments in today's China, namely internal migration and low fertility, 
the latter being a consequence of the onechild policy and radical shift to urbanization and migration. When generations live thousands of kilometers apart, the practice of filial piety becomes difficult since it must rely on grown-up children caring for frail parents from a distance, for instance, by paying someone to perform this role. This is only possible for families with a sufficient financial surplus and certain levels of trust, which, however, almost do not exist in today's China. Furthermore, when families only have one child, it is not feasible for one daughter or daughter-in-law to care for (up to four) frail elderly parents, even if they live within the same geographical area (Abrahamson 2011).

\section{Women AND Welfare In CHINA}

The work unit or the collective farm acted as a comprehensive system of support and help in the early history of the People's Republic. However, following the reform period from 1978 these systems broke down, and the market was expected to be as successful, if only for a while, regarding welfare provision as it had proved to be in distributing other items of consumption. However, it became clear that market-led welfare provision exacerbates societal inequalities, hence it contributed to, rather than reduced, the overall inequality in Chinese society. Therefore, beginning with the Asian financial crisis in 1998, China started to develop comprehensive social security systems in relation to health care and old-age pensions. From 2007 a program of universal social assistance was established, and the problem of migrant workers' limited access to social services was recognized: "In recent years, the Chinese government seems to be questioning whether the 'private welfare' model is the right path for China after all" (Warnecke 2009: 6).

Thus, changing welfare regimes have resulted in changing gender regimes in
China. Undoubtedly, the first period of the People's Republic, from 1949 to 1978, meant a great leap forward for women's rights and the recognition of women, perhaps not surprisingly, since it happened against the backdrop of a traditional feudal order. In urban areas, work units were responsible for providing work and taking care of those without the capacity to work (the so-called 'three no's'), and provided collective child care and cafeterias, which eased the burden of domestic work.

In the post-socialist era, the gradual privatization of social security and inequalities between men and women increased, since entitlements now reflected labor market participation and pay. Meanwhile, stateowned enterprises were no longer able to deliver social services and transfers, and many were left without coverage, such as pensions and unemployment benefits. Gradually, and more intensively since the Asian crisis of 1998, contributory social security systems for old age and health care were established, and now in the 2010s they cover the great majority of the population. But in general, contributory systems favor men rather than women, because they work longer hours, are better paid and are allowed to work for more years. The last issue is a consequence of the very low retirement ages in China, particularly for women, who are usually forced to retire at 50 or 55 , while men retire at 60 (Chan, Ngok, Philips 2008: 65). This low retirement age is a mixed blessing, especially for women. Many women never make it to higher positions within labor market hierarchies, and therefore they have lower pensions than men do. Furthermore, pension funds are far from mature, meaning that the compensation is very low. Hence, most of the elderly in China are in practice still dependent upon their family relatives.

Differences between men and women are also reflected in the general development of the Chinese labor market, with its enormous internal migration since that 
marked was opened up, and the process is becoming increasingly feminized. (Young) women are recruited from the countryside to work in factories or service jobs in the cities and the so-called Special Economic Zones, the export-processing zones. Regarding social citizenship, migrant workers experience the effects of the socalled hokou system of spatial registration, which divides the Chinese population into two groups, depending on whether they live in rural or urban areas: one can only receive welfare entitlements where one is registered, meaning that migrant workers cannot exercise their social rights at their place of work, including schooling for their children (Warnecke 2009: 12). This situation is gradually changing, and some measures have now been adopted in the direction of a more flexible form of citizenship, while certain migrant facilities have also been allowed to establish themselves outside the factories.

On paper, women are protected and given rights in connection with child birth, but in reality: there is evidence to suggest that women are increasingly pressured to defer marriage and childbirth in order to retain jobs. Due to the lack of labor law enforcement, when women (particularly rural migrant women) become pregnant, it is simply easier to substitute them with replacement workers rather than pay them maternity leave. Such trends reinforce the (involuntary) decision to either work or bear children, but not to combine the two. (Wanecke 2009: 13)

Furthermore, it has proved difficult for many women to exercise their rights to return to their jobs after giving birth, or even just to go on leave: "A regulation barring female teachers from maternity leave in their first three years of service at a high school in Shizuishan was revoked after it was disclosed in the media" (China Daily 2014a: 2). With the recent relaxation of the one-child policy, the working condi- tions of mothers were highlighted as illustrated by the example below: "Miao Zhiming has had a choice to make: child or job? The 31-year-old Shanghai resident is planning to have a second child this year... [but that] probably means she will lose her job" (China Daily 2014b: 1). It is expected that many women will experience the same dilemma, since employers are hesitant to hire women who plan to give birth.

\section{Who Cares? The Case of Shanghai}

It should be stressed that reflections on China in this article relate to urban, modern China. This section discusses the welfare mixture regarding care for the elderly in the most advanced part of the country, namely Shanghai. Of utmost importance are the possible changes to the overall value systems that prevail in Chinese society. Sun and Wang (2010: 76) found that the younger generations in Shanghai have shifted from traditional toward more modern values, being more secular - they consider self-development to be more important than making a contribution to society - and more individualistic. Four different generations were asked about "Lei Feng's spirit" 1 in order to determine whether they were collectively or individually oriented. Among the old generation, nearly 60 percent of the sample strongly agreed, but only 25 percent of the younger generation strongly agreed. However, more surprisingly, some spiritual concerns and traditional beliefs have persisted, chiefly in relation to family values. In the survey, all four generations agreed that "family is important in people's life." Strongly related to family values is the question of filial piety. Cheung and Kwan (2009) investigated this in relation to modernization in the form of urbanization, concluding that city-level modernization has an influence on Chinese people's filial piety. "The findings support the notion that when Chinese adult children take up jobs and live in 
places far away from their parents, filial piety is reduced" (Cheung and Kwan 2009: 190, emphasis added). However, daughters practice filial piety more than sons.

The Chinese sociologist Yifei Shen (2011: 20) concluded that, "it is no longer possible to acquire dominant rights in the household merely based on the status of father, and a father's power must be supported by other factors such as money or social status.... In this sense the classic patriarchy has already broken down." This leads her to talk of post-patriarchy, and to include a perspective on generations:

in the adult to pre-retirement cohort, two entirely different tendencies emerge in the social status of the two genders: within the power hierarchy of 18-65-year-old males, hierarchical status increases with age, whereas in the power hierarchy of 18-65-year-old females hierarchical status decreases with age.

(Shen 2011: 20-21)

Shen suggests that women's powers are at their greatest when they are young girls. They also have a big say in their marriages, generally more so than their boyfriends. After marriage, men and women tend to have relatively equal rights, but the status of women declines with age, and by the time a woman becomes a mother-in law, her powers are at their nadir. For men it is the opposite: their powers increase with age and length of marriage. Zhang and Goza (2006) interviewed members of what has been called the sandwich generation, and they found that it is impossible for a single child to care for two parents and four grandparents. Hence, alternative ways of caring for the frail and elderly must be sought out. They praise what they label the exemplary Shanghai model, where neighborhood committee volunteers provide support for the elderly. The volunteers are mostly young-old who then care for the old-old.

The general assumption is that moderni- zation leads to de-familialization, but in the East Asian case this is more complex. Izuhara and Forest (2013) compared three generations of families in Shanghai and Tokyo with reference to housing, finding processes of both defamilialization and refamilialization. First and foremost, they concluded that the family is far from having become an anachronistic institution; rather, it remains an active domain that seeks to maximize benefits and opportunities for all its members. The traditional role of families appears to be quite robust, and family support remains the dominant form of welfare provision. Furthermore, "in urban China, the unprecedented pace and degree of transformation regarding housing, work and family has been experienced by the current middle generation. Thus, in Shanghai, the generational gap appeared to be wider between the middle generation and both the younger and older generations" (Izu-hara and Forest (2013: 535). The authors also found that socio-economic and policy changes supported the increasing independence of older generations from their adult children, while the recent crisis and house price inflation was reinforcing the family dependence of the younger generation.

Sabet (2011) interviewed 21 young people of the so-called balinhou or post-80s generation in Shanghai and found that they are faced with a "landscape of paradoxes": the co-existence of communism and a market economy, a collectivist culture combined with fierce competition and the pursuit of career versus the importance of family. "They do not reject traditional Chinese or foreign cultural influences, [but] they do not readily embrace them either" (Babet 2011: 549). The post-80s generation consider themselves to be selfdetermining, but within certain constraints. Similarly, Xu and Yeung (2013) looked at family and gender relations by examining fathers' involvement in their adolescent daughters' lives in Shanghai, and they 
found that, contrary to the stereotypical understanding, fathers were nurturing and greatly involved in many aspects of their daughters' lives. Hence, the perception of men in Shanghai is unique because Shanghai society currently "stresses both traditio-nal views of male strength through work and men's affectionate care at home. In Shanghai, men have a reputation of being henpecked. A specific Shanghai term, madasa $0,{ }^{2}$ is often used to describe a typical Shanghai man who is devoted to family life" (Xu and Yeung 2013: 189). He is often referred to as the "bag carrier" because he carries his wife's or girlfriend's bags when they are shopping. Based on both a survey and interviews, the authors con-cluded that both parent-child relations and gender roles have become more egalitarian because of reforms introduced by the Chinese Communist Party and governments since the 1950s. Since the introduction of the one-child policy, many parents have concentrated their investment in their only child, regardless of its gender.

In recent years, rapid privatization and globalization have greatly enhanced the value of human capital and increased competition for life opportunities. These social forces together have reduced the gender bias in fathering behavior that has been deeply rooted in traditional Chinese families and prompted Shanghai fathers to be highly concerned with their daughters' academic success. (Xu and Yeung 2013: 203)

Yet another phenomenon challenges the traditional understanding of gender and generation in Shanghai, namely that of sheng nü, or "left-over women". This refers to highly educated, professional women who never marry because of discrimination in the marriage market (see the review of Leta Hong Fincher's book in this issue). While the official understanding is that they are unmarried because of their "overly high expectations for marriage partners" (Mini- stry of Education 2007, quoted in To 2013: 2), Sandy To (2013: 17) found instead that it was the persistently formidable nature of the Chinese patriarchal structure that led to "discriminatory" and "controlling" gendered constraints that barred most professional women from marriage:

It was found that many of the Chinese professional women had been rejected by their male romantic partners and suitors because of their strong economic accomplishments. Men harboring "male superior norms" was seen as main causes that rendered the highly educated professional women "leftover" in the marriage market (To 2013: 10).

A parallel phenomenon applies to men who cannot find a spouse because of the biased sex ratio in Chinese society, an unintended consequence of the one-child policy that has led to a situation where there are only eighteen young women for every twenty young men, the so-called bare branch phenomenon:

When there is a deficit of women, poor men are not able to find wives, which can result in the creation of bare-branch villages that suffer from inconvenient transportation, an underdeveloped economic environment and a difficult lifestyle...some wealthy communities also experience the bare-branch phenomenon. (Quanbao and Sánchez-Barricate 2013: 112113)

Hence, traditional value systems are being challenged, but they do to some extent resist the challenges, leaving Chinese families in doubt and confusion.

\section{The Welfare Mix of Care IN SHANGHAI}

In 1998 China decided to introduce what has been labeled socializing social welfare or the welfare socialization reform with the purpose of involving "social forces" in the 
delivery of social policy, which means inviting the NGOs or NPOs (non-governmental or non-public organizations) onboard, hence adopting a truly mixed welfare approach. At the end of 2008 China had more than 182,000 NPOs, nearly half of which (44\%) were welfare organizations, which "have now surpassed the state as welfare provider of old age care in China today" ( $\mathrm{Li}$ and Wong 2010: 2-3). This mixed welfare approach is well illustrated in the case of Shanghai, where the $12^{\text {th }}$ FiveYear Plan (2011-2015) suggests a senior care system that is largely based on homebased care, supported by community care, and supplemented by organization care. The structure is characterized as "9073", meaning that 90 percent of the elderly receive home-based care with the help of family members or trained nursing workers, 7 percent receive community nursing service, such as day-care centers and 'meals on wheels' programs, while 3 percent rely on nursing homes. The plan places considerable importance on long-term care at home, yet there are few trained nurses or nurse's aides available on the market to work in homes (Shanghai Daily 2012: B2).

\section{Table 1. Senior care organizations}

(nursing homes) in Shanghai in 2011

$\begin{array}{lcl} & \text { Organizations } & \text { Beds } \\ \text { Public } & 33 & 9,070 \\ \text { Community } & 263 & 39,633 \\ \text { Private } & 335 & 53,193 \\ \text { Total } & 631 & 101,896\end{array}$

Source: Shanghai Daily (2012: B2)

This breakdown is unfortunate since public nursing homes are by far the most popular of these in general rather unpopular forms of elderly care. The public ones are relatively affordable, and the older generation trusts public organizations more than pri- vate ones. Furthermore, private solutions are only relevant for an affluent minority because of their high costs, which show up in the high vacancy rates within this sector.

China Senior Care, which is building a 64bed acute-care facility in Hangzhou, plans to charge at least 40,000 renminbi, or $\$ 6,300$, per month, putting the facility far out of reach for all but the wealthiest in China... At Cherish-Yearn, an upscale retirement community on the outskirts of Shanghai, Chairman Xi Zhiyong has invested 600 million renminbi to build 800 apartments, with a little more than 60 percent of them full (New York Times 2012).

This judgment is widespread: "In Shanghai, the government-owned nursing homes, which are more affordable, are all full, and those on the waiting list need to wait for over five years before having a chance to enter" (Kleinman 2012). A similar situation also prevails in Chongqing: "After a few years of development of privately owned nursing homes, about 140 such facilities were opened in Chongqing. A few soon filled up, typically with wealthier aged residents, but over half of the nursing homes cannot get enough customers or face bankruptcy" (ibid.).

To support home care, Shanghai has introduced day-care centers for citizens over 65. There are now 326 such centers across the city, which is an increase from the year before of 8 percent (Shanghai Daily 2012: B2). These rely, at least to some extent, on co-operation with voluntary organizations such as the Hands On: "Hands On volunteers engage the elderly in fun activities to enliven the elders' daily schedules. Volunteers will play BINGO and mahjong, assist with rehabilitation classes, teach English, keep up the garden, and engage in a lot of very interesting conversations" (Hands On Shanghai 2013). These activities, which are provided by volunteers, are additional to services such as daily 
meals and physical check-ups. Shanghai plans to build another twenty day-care centers for the elderly and forty sites for delivering meals to them in residential complexes by the end of 2013 (China Daily 2013).

\section{Caring in Copenhagen}

This section focuses on care of the elderly in Denmark as an illustration of the relationships between the welfare regime and the gender and generation regimes. Every Danish citizen is entitled to services free of charge if they are in need, and both men and women have access to the public old age pension system when they turn age 65 (67) regardless of their private economic status. Both social care services and the public old-age pension are financed through taxes. On the one hand, the system of care services is decentralized with the legal responsibility for providing the elderly with both practical and personal help placed at the local government level. It is the municipalities that pay for the services through local taxes and block grants from the state, set the standards of help and decide how much help a person is entitled to, based on individual needs. The pension system, on the other hand, is centralized, with national standards regulating the size of public old age pensions etc.

The aim of the help offered is to allow elderly people to stay in their own homes as long as possible and to protect them from declining physical and mental health. This means helping people in their own homes even when they need help to clean the house or get out of bed in the morning. Today around 200,000 people receive permanent home-care services, with between 1.0 and 1.1 million care hours being delivered every week to $25 \%$ of all citizens aged 67 and older. The local council is required to set up and publish so-called quality standards. It must not only provide information about its services, but also ensure that citizens are fully informed about their rights in relation to the local authority. The quality of the standards and the actual services provided for the elderly must meet the requirements conditioned in the laws governing social services (Ministry of Social Affairs and Integration 2013).

A large-scale reform of housing for the elderly was implemented in 1988. Before that year, residential accommodation for the elderly was thought of as "old people's homes." The basic principle of the reform was on the one hand to make it possible for the elderly to stay in their own homes for as long as possible. On the other hand, it was also intended to increase the standards of residential accommodation. Today, there are many different types of housing in Denmark: the family home, close-care accommodation, private nursing homes and in the coming years a new type called friplejeboliger (private nursing homes/private dwellings). As with home care services, it is the municipalities that determine whether a citizen requires the kind of help that cannot be given in the private home. If a citizen is offered residential accommodation, she or he can decide between the different alternatives in the municipality or even move to another municipality. In 2006 there were around 90,000 homes suitable for the elderly, of which 45,000 provided round-the-clock services from permanent staff. A care home guarantee has been granted since 2009 , so that citizens eligible for nursing homes will have to wait no more than two months for a place to stay (Ministry of Social Affairs and Integration 2013).

Ideally, the Scandinavian welfare regime has relieved the younger generations, especially younger women, from the "burden" of care for the elderly. But in reality, the insufficiency in collective care arrangements has led to a situation in which civil-society actors such as family members, neighbors and NGOs have had to fill the gaps. Hence, the municipality of Copenhagen is 
Table 2. Sources of care for the elderly in Copenhagen

Source of care

Family and/or friends

Not-for-profit organizations

Public authorities

Private carers/for-profit firms
Home care (\% share)

10

0

62

28
Institutional care (\% share)

n.a.

0

100

0

Source: Sjørup 2010.

currently reacting to the increasing number of frail elderly by reducing the total number of hours allocated to home help and help in old age from 13,060 hours to 12,700 hours at a time when the number of recipients has increased from 53,200 to 56,000 , resulting in fewer elderly people receiving help (Statistics Copenhagen 2013). Table 2 demonstrates how the public sector is nonetheless still providing twothirds of the total amount of elderly care in Copenhagen.

The administrative reform of 2007 strengthened the municipal dimension of elderly care, first, by giving the responsibility for rehabilitative and preventive measures to the municipalities, and secondly, by providing financial incentives for the municipalities to establish rehabilitation and prevention programmes. In other words, in this case practices were implemented that conform to the discourse of economic efficiency and, at the same time, reproduce them when it comes to rehabilitation in elderly care. Thus, the strong emphasis on economic efficiency on the part of local policy actors makes sense (Fersch 2012: 14).

Sjørup furthermore talks about a "fourgeneration society", meaning two groups of elderly, the young and the old: $60-74$ and 75-108; and the young, 0-24, and working age generations, 25-59 (Sjørup 2010: 18). The care problem refers particularly to the very old as those needing care, and to the middle generation as those sup- posed to deliver some care. Sjørup (2010: 14) states that "the overall shift in policies of elderly care for the last 10 years has been the shift from the social democratic model of welfare as a complex of rights for a certain age group to the policy of New Public Management." This observation we also find in Jensen and Fersch (2011: 2) when they write: "As in other European countries, the elderly care reform in Denmark was inspired by liberal and libertarian values, epitomized as the 'freedom of choice'.... This constructed them as consumers of welfare services." They conclude:

Because there is no real competition over price, the only incentive for care receivers to choose a private instead of a public provider are, first, that clients feel more comfortable with a private rather than a public provider of care, and, secondly, that private providers, contrary to public providers, are allowed to offer additional services (Jensen and Fersch 2011: 11).

Pernille Hohnen (2011: 1) agrees with this reasoning and qualifies the conclusions when she states:

Privatization in Danish elderly care has generally not taken place as outsourcing to one or more private providers based on a competition of price and quality. Instead, most municipalities have opted for the fixed-price arrangement, inviting private suppliers to provide the care in a free-choice system, 
where elderly receivers of care are entitled to choose between providers that have been accredited by the municipality. (Hohnen 2011:2)

Furthermore, "the tendency has been for municipalities to separate practical care (cleaning) from personal care - and to have private companies provide the larger part of practical care, keeping most personal care provision within the municipal care units" (ibid.). Thus, with respect to elderly care, Denmark is moving away from the idealtypical Scandinavian regime towards one influenced more by the Conservative and Liberal regimes.

\section{CONCLUSION: COMPARING WELFARE COMBINATIONS IN CARE FOR THE ELDERLY IN CHINA AND DENMARK}

The frail elderly need to both be provided and cared for, and even when the state has taken formal responsibility for this, the actual delivery of support and care may very well come from the market for those who can afford it - that is, a rich minority from the family, which very often means daughters and daughter's-in-law, from the community in the form of NPOs and NGOs, or from the state, meaning both central and local government. In both the Chinese and Danish cases all sectors of the welfare diamond are involved in the care and support of elderly citizens, but in Denmark the public sector is much more involved than is the case in China. However, as in China, the Danish local state mostly provides home care. Only four percent of Danes aged 65 or over are in an old-age home (NOSOSKO 2013: 133), and as we have seen China aims at three percent, thus creating a quite similar situation. But when it comes to home care, while China wants to leave 90 percent of the elderly to their families, in Denmark that share is "only" 38 percent.

Furthermore, private alternatives are more widespread in China, indicating a higher degree of differentiation and possible polarization along class lines. The continued strong reliance on family support and care in China poses serious challenges along the lines of gender and generation. It is first and foremost women within families who are expected to provide care, while the support burden is shared between husband and wife in the younger generations, that is, precisely those generations that are facing the toughest dilemmas in contemporary China. The traditional intergenerational support system is being challenged by new norms, new spatial distributions and women's formal engagement in labor market and careers, plus the fact that there are relatively few women in the younger cohorts due to the one-child policy. Greater public responsibility and involvement is one answer, as the Danish case demonstrates, but this presupposes a willingness to pay much higher taxes than is presently the case in China.

It seems that the very different welfare regimes of Scandinavia and China are converging towards a model of a welfare combination within an overall framework of universalism. Ideally, this is the best of all worlds, but in reality it poses challenges along the parameters of class, gender, generation and ethnicity. However, unlike earlier times, while class and gender remain important, the most important line of conflict now revolves around generation.

\section{Notes}

1. Lei Feng was a soldier who died on duty in the 1960s during the Great Leap Forward. He was idealized by the Chinese authorities as an ideal typical collectively oriented person through pictures, film clips and later extracts from his diary, the authenticity of which has been questioned. 2. "Ma da sao is Shanghai slang, meaning, 'shop, wash, cook.' Because sao (cook) has the same pronunciation as the word for an older woman, when 
Chinese hear the term "ma da sao," they usually picture a housewife. The exception is when the term is used to describe men in Shanghai - guys who don't just shop, wash and cook, but famously do so without complaint" (He 2011).

\section{LITERATURE}

- Abrahamson, Peter (2014). 'Harmony and welfare state development.' Journal of Tianjin Administration Institute Vol.16, No.2: 100-110 [in Chinese]. Forthcoming in English in Helge Geir and Ras Nielsen (eds) Harmony: Eastern and Western Perspectives? [Working title] Copenhagen: NIAS Press.

- Abrahamson, Peter (2011). 'The welfare modelling business revisited: the case of East Asian welfare regimes.' Gyu-jin Hwang (ed.) New Welfare States in East Asia: Global Challenges and Restructuring. Cheltenham: Edward Elgar Publishing Ltd., pp. 15-34.

- Abrahamson, Peter (2010). 'European welfare states beyond neoliberalism: toward the social investment state.' Development \& Society Vol. 39, No. 1: 61-95.

- Borchorst, Anette (2012). 'Reassessing womanfriendliness and the gender system: feminist theorizing about the Nordic welfare model.' In Anttonen, A. Häikiö, L. \& Stefansson, K. (ed.). Nordic Universalism: Equality and Diversity in Social Policy, s. 106-120. Bristol: Policy Press.

. Chan, Chak Kwan; Ngok, Lun; and Philips, David (2008): Social Policy in China: Development and Well-Being. Bristol, Policy Press.

. Cheung, Chau-Kiu and Kwan, Alex (2009): 'The erosion of filial piety by modernization in Chinese cities.' Aging \& Society 29: 179-198.

. China Daily (2013). 'China to improve standard for elderly care.' China Daily 7 September.

- China Development Research Foundation (2012): Constructing a Social Welfare System for all in China. London, Routledge.

- China Daily (2014a): 'School revokes maternity rule.' China Daily $20^{\text {th }}$ March.

. China Daily (2014b): 'Advisers offer help on second-child dilemma.' China Daily $8^{\text {th }}$ March. - Fersch, Barbara (2012): 'Combining activity and economic efficiency? The view of Danish local policy actors on rehabilitation in elderly care.' Paper, Aalborg University.

- Gough, Ian, Wood, G, Barrientos, Amando, Bevan, P, Davis, P, and Room, Graham (2004): Insecurity and Welfare Regimes in Asia, Africa and Latin America. Cambridge, Cambridge University Press.

. Hands On Shanghai (2013).

http://www.handsonshanghai.org/

· He, Helen (2011): 'China surpasses the world in yet another category: Quality husbands.' CNN: http://travel.cnn.com/shanghai/life/china-surpasses-world-yet-another-category-quality-husbands-388851.

- Hernes, Helga (1987). Welfare State and Woman Power: Essays in State Feminism. London: Norwegian University Press.

- Hohnen, Pernille (2011). Elderly care in

Denmark. Brussels: WALQING.

. Izuhara, Misa and Forrest, Ray (2013): “"Active families": Familization, housing and welfare across generations in East Asia.' Social Policy \& Administration 47(5): 520-541.

- Jensen, Per H. \& Fersch, Barbara (2011):

'Experiences with the privatization of home care: evidence from Denmark.' Nordic Journal of Social Research Special Issue: 1-14.

- Kettunen, Pauli; Kuhnle, Stein; and Ren, Yuan (eds.) (2014): Reshaping Welfare Institutions in China and the Nordic Countries. Helsinki, Nordic Center of Excellence NORDWELL.

- Kleinman, Arthur and , Hongtu (2012). 'Looking after the Elderly: Asia's Next Big Challenge.' http://www.fungglobalinstitute.org/publications/articles/looking-after-the-elderly-asiasnext-big-challenge-286.html.

· Li, Na and Wong, Linda (2010). 'Changing institution and evolution of Chinese Welfare NPOs: cases from urban old age homes in Shanghai.' Paper. City University of Hong Kong.

- Ministry of Social affairs and Integration (2013): Social Issues - Elderly People.

http://english.sm.dk/social-issues/Elderly-people/Sider/Start.aspx

- New York Times (2012). 'Old Age in China Is a Fledgling Business Opportunity.' l October.

- NOSOSKO, 2013. Nordisk socialstatistikkomité - Quanbao, Jiang and Sánchez-Barricate, Jesús (2013). 'Socio-demographic risks and challenges of bare-branch villages in China.' Asian Social Work and Policy Review 7(2): 99-116.

- Sabet, Denise (2011): 'Confucian or communist, post-Mao or post-modern? Exploring the narrative identity resources of Shanghai's post-80s generation.' Symbolic Interaction 34(4): 536-551.

- Shanghai Daily (2012). 'China's elder-care woes.' Shanghai Daily: B2. 26. June.

- Shen, Yifei (2011): 'China in the "post-patriarchal era:" changes in the power relations in urban households and an analysis of the course of gender 
inequality in society.' Chinese Sociology and Anthropology 43(4): 5-23.

- Sjørup, Karen (2010): Elderly care in Denmark: Provisions and providers. Roskilde University, Danish National Report.

- Statistics Copenhagen (2013). Stat Bank.

- Sun, Jiaming and Wang, Xun (2010): 'Value differences between generations in China: a study in Shanghai. Journal of Youth Studies 13(1): 65-81.

. To, Sandy (2013): 'Understanding shen nü (leftover women): the phenomenon of late marriage among Chinese professional women.' Symbolic Interaction 36(1): 1-20.

. Warnecke, Tonia (2009): 'Gender and the wel fare state in China.' AACS Annual conference, Rollins College.

. Wood, G and Gough, Ian (2006): A comparative welfare regime approach to global social policy.' World Development 34(10): 1696-1712.

· Xu, Quing and Yeung, Wei-jun (2013): 'Hoping for a phoenix: Shanghai fathers and their daughters.' Journal of Family Issues 34(2): 184-209. - Zhang, Yuanting and Goza, Franklin (2006): 'Who will care for the elderly in China? A review of the problems caused by China's one-child policy and their potential solutions.' Journal of Aging Studies 20: 151-164. 